\title{
COMO OCORREU O PROCESSO DE TÉRMINO DA CARREIRA ESPORTIVA DE EX-ATLETAS DE FUTEBOL QUE DISPUTARAM COPAS DO MUNDO PELO BRASIL ENTRE 1966 E 1982?
}

\author{
Cleiton Pereira Reis \\ Universidade Federal de Minas Gerais, Belo Horizonte, Minas Gerais, Brasil. \\ Marisa Lúcia de Mello Santiago \\ Universidade Federal de Minas Gerais, Belo Horizonte, Minas Gerais, Brasil. \\ Márcia Cristina Custódia Ferreira \\ Instituto Federal Goiano, Morrinhos, Goiás, Brasil \\ Maicon Rodrigues Albuquerque \\ Universidade Federal de Minas Gerais, Belo Horizonte, Minas Gerais, Brasil. \\ Eduardo Mendonça Pimenta \\ Universidade Federal de Minas Gerais, Belo Horizonte, Minas Gerais, Brasil. \\ Varley Teoldo da Costa \\ Universidade Federal de Minas Gerais, Belo Horizonte, Minas Gerais, Brasil.
}

\begin{abstract}
Resumo
O objetivo do estudo foi analisar o término da carreira de ex-atletas de futebol que disputaram Copas do Mundo pelo Brasil entre 1966 e 1982. Foram realizadas entrevistas semiestruturadas com seis ex-atletas. As entrevistas foram analisadas por meio de miniunidades. O conteúdo das entrevistas foi organizado em cinco categorias. Os resultados apontam que os ex-atletas não tiveram acesso a uma estrutura profissional para planejar o término da carreira. Eles não conseguiram conciliar a carreira esportiva com os estudos. Foram citados como motivos para o término da carreira: a saturação psicológica, lesões e idade avançada. Os entrevistados tiveram diversas ocupações no pós-carreira, muitas delas relacionadas com o meio esportivo. A família foi a maior fonte de apoio durante o término da carreira. Conclui-se que as causas da aposentadoria dos entrevistados foram multifatoriais e que os ex-atletas não tiveram um planejamento estruturado para o término da carreira esportiva.
\end{abstract}

Palavras-chave: Aposentadoria. Atletas. Futebol.

\section{Introdução}

O término da carreira esportiva pode ser visto como um momento crítico, principalmente quando o ex-atleta não realizou um planejamento estruturado para enfrentar esta situação (STAMBULOVA et al., 2009). Esse período da vida do ex-atleta é considerado como uma fase de transição, já que não é um evento único, mas sim um processo complexo e multifato- 
rial resultado de um longo período de decisões pessoais e profissionais tomadas (LOTYSZ; SHORT, 2004; ZHANG et al., 2013; VILANOVA; PUIG, 2014; WYLLEMAN; ROSIER; De KNOP, 2016).

O modelo conceitual do término da carreira esportiva de Taylor e Ogilvie (1994) descreve os fatores que influenciam decisivamente o término da carreira: causas para o término da carreira esportiva, adaptação ao término da carreira, fatores estressantes em relação ao término da carreira e recursos de coping ${ }^{1}$ para enfrentar o término da carreira. O término da carreira pode ser caracterizado também pelo ingresso do ex-atleta em alguma outra atividade laboral e pela mudança do status social, o que inclui um novo estilo de vida e novas perspectivas nas relações sociais (STAMBULOVA; WYLLEMAN, 2014; KUETTEL; BOYLE; SCHMID, 2017).

A respeito do término de carreira de ex-atletas de futebol, Fernández e Moreno (2012) investigaram tal fase em ex-atletas profissionais da primeira e segunda divisão espanhola. Os principais resultados apontam que, para aqueles que conseguiram se reinserir em um novo contexto do mercado de trabalho com sucesso, foram necessários: um planejamento estruturado de carreira, reservas financeiras, retorno aos estudos e uma vasta e sólida rede de contatos pessoais e profissionais. Já Jones e Denison (2016) estudaram ex-atletas ingleses de futebol e verificaram principalmente que esses indivíduos se sentiam aliviados perante a aposentadoria, já que eles não precisariam mais se submeter a uma rotina desgastante de jogos e treinamentos. Porém, muitos deles consideraram que estavam despreparados para enfrentar uma nova realidade social fora do ambiente esportivo. Estudos com ex-atletas brasileiros mostraram que aspectos como a retomada dos estudos, a busca pela formação acadêmica, a dedicação à família e a inserção em outros grupos sociais fora do contexto esportivo são fundamentais para uma transição adequada (SAMULSKI et al., 2009).

Especificamente com ex-atletas de futebol brasileiro, existem poucos trabalhos que investigaram o término da carreira esportiva, e esses poucos trabalhos não foram realizados com atletas de seleção brasileira. Agresta, Brandão e Barros Neto (2008), ao estudarem o término da carreira de atletas profissionais de futebol, observaram que, apesar de os atletas terem experimentado uma carreira esportiva longa, o momento da aposentadoria trouxe sentimentos de tristeza. Já Costa et al. (2010) investigaram 25 ex-atletas profissionais brasileiros de futebol e constataram que os principais motivos citados para o término da carreira esportiva foram: excessivas lesões, idade avançada, necessidade de uma dedicação maior à família e falta de motivação para se manter na excelência esportiva. $\mathrm{O}$ estudo de Arliani et al. (2014) focou em investigar, após o término da carreira esportiva, o estado de saúde de ex-atletas profissionais do futebol brasileiro. Os resultados apontaram que $78 \%$ deles estavam com sobrepeso e $97 \%$ deles apresentaram algum tipo de dor nos joelhos. Essas dores foram associadas às situações de uso excessivo das principais articulações para fins esportivos e também pelo alto nível de sedentarismo desses indivíduos.

Considerando-se os estudos supracitados, as evidências científicas sobre o término da carreira de ex-atletas do futebol brasileiro ainda são escassas. Isto acontece devido ao número reduzido de investigações sobre a temática, em especial estudos envolvendo atletas que atingiram a meta de vestir a camisa da seleção brasileira de futebol e disputar uma Copa do Mundo. Sabe-se que o alcance deste patamar é um privilégio para poucos em razão da concorrência e da qualidade dos atletas de futebol no Brasil. Torna-se importante investigar o término da carreira de ex-atletas de futebol em um período em que a profissionalização da modalidade era incipiente.

1

Conjunto de esforços cognitivos e comportamentais utilizados pelo indivíduo com o objetivo de controlar, reduzir ou tolerar as demandas específicas internas ou externas que surgem em situações de estresse e que são avaliadas como sobrecargas (LAZARUS; FOLKMAN, 1984). 
Os atletas de futebol que chegaram a vestir a camisa da seleção brasileira têm o status de ídolos. Porém, hipoteticamente, o fato de esses indivíduos terem atingido o auge da aspiração esportiva (vestir a camisa da seleção nacional do seu país) não garante necessariamente um término de carreira bem-sucedido. Entre 1966 e 1986, o futebol brasileiro vivia um período particular, no qual praticamente todos os atletas da seleção brasileira ainda jogavam em equipes dentro do próprio país. Posteriormente à Copa de 1982, alguns atletas da seleção brasileira de futebol começaram a migrar para equipes estrangeiras, principalmente para clubes europeus (FERNANDES, 2009). Devido à menor rentabilidade financeira e à estrutura esportiva pouco profissional do futebol brasileiro entre os anos de 1966 e 1982, em comparação aos dias atuais (SILVA JÚNIOR; SALAZAR; FEITOSA, 2014), tem-se como hipótese para o presente estudo que os ex-atletas que disputaram Copas do Mundo pelo Brasil não tiveram a oportunidade de realizar um planejamento estruturado para o término da carreira em função das condições de outrora.

Assim, o objetivo do estudo é analisar o término da carreira de ex-atletas de futebol que participaram de Copas do Mundo pela seleção brasileira entre 1966 e 1982.

\section{Metodologia}

O presente estudo buscou analisar o término da carreira de atletas de futebol que disputaram Copas do Mundo pelo Brasil por um viés qualitativo (PATTON, 2015). Dentro desta linha de investigação, outros estudos também analisaram o término da carreira de esportistas através de métodos qualitativos e entrevistas retrospectivas (VILANOVA; PUIG, 2014; JONES; DENISON, 2016).

O estudo foi aprovado pelo Comitê de Ética em Pesquisa da Universidade Federal de Minas Gerais, sob o número de protocolo ETIC 293/08. Todos os participantes assinaram um Termo de Consentimento Livre e Esclarecido.

Dos 82 atletas brasileiros convocados para as Copas do Mundo da Fédération Internationale de Football Association (FIFA), entre 1966 e 1982, os pesquisadores conseguiram fazer contato com 49 ex-atletas. Destes, 6 ex-atletas (média de idade de 61,17 \pm 4,95 anos) aceitaram participar do estudo (12,24\%). Todos os entrevistados jogavam em clubes brasileiros na época que disputaram Copas do Mundo de Futebol. Os entrevistados encerraram a carreira com 33,50 $( \pm 5,61)$ anos em média.

Entre 1966 e 1982, o Brasil disputou 28 jogos oficiais de Copa do Mundo. Desses 28 jogos, em 18 deles pelo menos um dos ex-atletas avaliados chegou a entrar em campo. Dos seis entrevistados, três foram campeões mundiais. Os ex-atletas atuavam nas seguintes posições: dois meio-campistas (Copa de 1982), dois atacantes (1970 e 78), um lateral (1974 e 1978) e um zagueiro (1966 e 1970).

Foram realizadas entrevistas retrospectivas semiestruturadas (PATTON, 2015). O roteiro da entrevista foi elaborado por cinco especialistas doutores na área de Psicologia do Esporte e especialistas em Futebol, conforme recomendações da literatura (CÔTÉ; ERICSSON; LAW, 2005). Todos os itens avaliados tiveram a concordância dos peritos acima de $80 \%$. Os especialistas se basearam principalmente no questionário Athletic and Post Athletic Questionnaire (APAQ) (HACKFORT; EMRICH, PAPATHANASSIOU, 1997) para a elaboração do roteiro de entrevista. Outros estudos sobre a transição de carreira esportiva de atletas brasileiros de futebol também usaram o APAQ como base para a construção de um roteiro de entrevistas (AGRESTA; BRANDÃO; BARROS NETO, 2008; MARQUES; SAMULSKI, 2009).

Depois de um contato prévio com os ex-atletas, as entrevistas foram agendadas com aqueles que aceitaram participar do estudo. As coletas de dados foram realizadas nas 
residências ou no local de trabalho dos ex-atletas. A duração média das entrevistas foi de 1 hora e 30 minutos.

As entrevistas foram transcritas literalmente e reenviadas aos ex-atletas para conferência de conteúdo e validação da veracidade das informações. Após a aprovação do conteúdo pelos ex-atletas, as entrevistas foram encaminhadas a cinco doutores especialistas nas áreas de Psicologia do Esporte e Futebol para a análise dos dados (CÔTÉ et al., 1993; CÔTÉ; ERICSSON; LAW, 2005).

As transcrições das entrevistas foram divididas em pequenos trechos denominados unidades de significado, ou miniunidades (MUs). Elas são consideradas as menores partes compreensíveis de um texto que expressam uma ideia ou informação (TESCH, 1990). Para a identificação dos entrevistados, cada MU foi descrita com a letra A (ex-atleta) e um número de 1 a 6 . As narrativas foram categorizadas de acordo com as similaridades identificadas entre as diversas MUs estabelecidas (PATTON, 2015). Identificaram-se neste estudo 340 MUs, entretanto foram selecionadas apenas 165 MUs. Os critérios para a validação das 165 MUs foram: a) a narrativa (MU) deve representar uma ideia clara e ter uma relação direta com o objetivo do estudo; b) a MU deve atingir o consenso de $80 \%$ por parte dos avaliadores sobre a clareza das MUs; c) as MUs devem obter a concordância de $80 \%$ dos avaliadores na classificação dentro de cada categoria. As MUs foram classificadas de acordo com a similaridade de seus conteúdos (CÔTÉ et al., 1993, CÔTÉ; ERICSSON; LAW, 2005; PATTON, 2015).

A Figura 1 apresenta o resultado e a classificação categórica destas análises.

Figura 1 - Classificação categórica das MUs do estudo

Fonte: Elaborado pelo autor (2018).

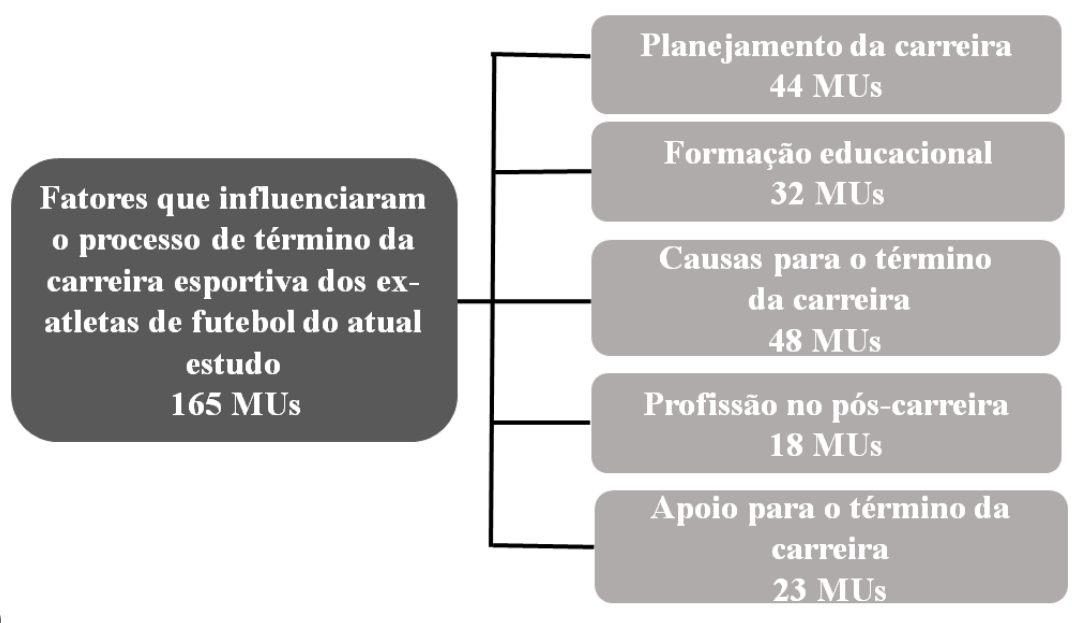

\section{Resultados}

A seguir, os resultados do estudo são apresentados em subtópicos (planejamento de carreira, formação educacional, causas para o término da carreira, profissão no pós-carreira, apoio para o término da carreira), de acordo com a classificação das MUs.

\section{Planejamento da carreira}

Mesmo sendo ex-atletas de renome no cenário esportivo brasileiro, apenas dois dos seis entrevistados fizeram algum tipo de planejamento para encerrar a carreira. No entanto, pode-se dizer que tal planejamento não foi realizado de maneira estruturada, com 
acompanhamento profissional, tampouco com suporte de natureza organizacional ou governamental. Apenas dois dos ex-atletas aposentadoria:

relataram que já pensavam durante a carreira na condição financeira para a

[...] e aí eu fiz o primeiro bom negócio, ao invés de comprar um carrão, eu comprei um posto de gasolina que eu tenho até hoje [...]. Eu não tive dificuldade de readaptação, não tive sofrimento. Eu já estava integrado perfeitamente, como qualquer outro trabalhador na sociedade. Não tive muito problema na minha aposentadoria (A2).

Eu fui me preparando para parar ao longo da carreira [...] isso eu casado, já tinha a academia de ginástica, com filhas, [...] dava saudade da minha casa e eu fui parando, então resolvi que ia parar em 1986 [...] mas nenhum clube ou entidade me ajudou no processo, algo formal, com profissionais para me ajudar. (A6).

Entretanto, quatro ex-atletas tiveram pouco ou não tiveram planejamento estruturado para o término da carreira. Tal fator trouxe grandes dificuldades de adaptação à vida de exatletas de futebol:

Parei de jogar futebol e tive que viver outra realidade. O jogador está em uma profissão que se dedica a vida toda, e na flor da sua idade, com 35 anos, encerra a carreira e não sabe fazer outra coisa [...] o jogador termina de jogar hoje, amanhã ele está desempregado. (A1).

O fim da minha carreira foi horrível. Foi com lágrimas nos olhos. Bem, eu pelo menos fui honesto comigo mesmo [...] eu passei uma dificuldade muito grande, tive que correr atrás. [...] pensei até em suicídio. Foi muito difícil para mim deixar de ser atleta. (A4).

Um dos entrevistados comentou que poderia ter feito melhores investimentos financeiros para o pós-carreira:

Se eu tivesse a cabeça que eu tenho hoje, eu teria uns vinte apartamentos no mínimo. O que eu ganhava na época dava para eu ter comprado vários apartamentos. Dava para eu ter juntado dinheiro [...]. Eu teria um bom patrimônio. Teve ano que eu troquei três vezes de carro. (A4).

\section{Formação educacional}

Quanto à formação educacional durante o período em que os entrevistados eram atletas, apenas um deles chegou a completar o segundo grau. Quatro dos seis entrevistados acreditavam que investir na carreira de atleta de futebol era o caminho mais viável para obter êxito profissional, em detrimento dos estudos. Como eles chegaram à seleção brasileira, o sucesso nos gramados era o principal foco durante a carreira. Além disso, um dos entrevistados citou que não gostava de estudar e, por isso, focou na carreira como atleta de futebol.

Eu nunca tive vontade de estudar, apesar do dirigente do meu clube me incentivar bastante na base [...] poderia ter ganhado o dobro que eu ganhei e lidar melhor com o dinheiro [...]. Eu tenho até o quarto ano do primeiro grau. Podia ter estudado mais [...] meu interesse era jogar futebol. (A5).

[...] e a partir do momento que eu comecei a trabalhar eu era responsável por mim mesmo. Formei no ensino médio, não dava mais para estudar, fazer faculdade, e continuar a jogar futebol [...]. Além disso, tinha a carreira como jogador de futebol, era difícil conciliar estudo e trabalho [...]. (A2). 
Apenas o entrevistado A3, mesmo no auge da carreira e sendo campeão do mundo de futebol, ressaltou a importância de se planejar para voltar aos estudos. Tal situação representou uma exceção na realidade desses indivíduos:

Quando o médico disse que eu não poderia jogar mais, no outro dia eu já estava olhando livros, vendo o que iria fazer [...]. Tive que fazer um grande esforço, e um ano depois eu já tinha passado no vestibular de medicina. Fiz o curso de medicina e me tornei médico. (A3).

\section{Causas para o término da carreira}

As principais causas para o término da carreira dos ex-atletas foram as lesões, a saturação psicológica e a idade avançada.

Comecei muito cedo e parei muito cedo, $[\ldots]$ tive que operar o olho duas vezes, [...] fui obrigado a encerrar a minha carreira contra a minha vontade, aos 26 anos. Já não dava para jogar mais. (A3).

Quebrei a mandíbula [...] operei o menisco da perna direita duas vezes, operei coluna uma vez, fiz biópsia no peito do pé. [...]. Foram várias lesões ao longo da minha carreira que contribuíram para eu parar de jogar. (A6).

A saturação psicológica é decorrente principalmente do excesso de viagens e de compromissos destes ex-atletas pelos clubes e pela seleção brasileira. Cabe ressaltar que os ex-atletas do atual estudo eram considerados decisivos em seus respectivos clubes, indivíduos que disputaram Copas do Mundo, e por isso, a cobrança por desempenho era sempre uma constante:

Não tinha mais paciência para jogar, para ficar em alojamento, ficar viajando [...] chega uma hora que você fica cansado de vários compromissos. Não tinha tempo de curtir a família e amigos. Queria passar mais tempo com a minha família, curtir mais [...]. (A5).

Eu já estava num momento que eu não treinava mais tão forte, não fazia aqueles treinamentos extras [...]. Isso eu casado, já tinha um negócio próprio: a academia. Tinha as minhas filhas, e dava saudade da minha casa [...]. Já estava na hora de pensar em parar mesmo. (A6).

O avançar da idade foi outra situação que contribuiu decisivamente para o término da carreira de um dos indivíduos entrevistados:

Bom, o fim da minha carreira foi horrível. Foi com lágrimas nos olhos [...]. Porque com 40 anos mandavam uma bola na área eu perdia no alto. Eu nunca perdia antes. Nesse momento vi que não dava para jogar mais. Preferi parar de jogar. (A4).

\section{Profissões no pós-carreira}

As profissões após o término da carreira dos entrevistados foram diversificadas. Notase que todos, em algum momento, voltaram a trabalhar no meio esportivo. O status de exatleta de seleção brasileira abriu portas para os entrevistados poderem trabalhar no meio esportivo. Um dos entrevistados se formou em medicina, dois deles se tornaram empresários em diferentes setores do comércio. Outro viés encontrado por três dos ex-atletas foi a carreira 
política, logo ou pouco depois do término da carreira de atletas de futebol, exatamente por já serem figuras públicas reconhecidas no país:

Em 1972, fui ser vereador, uma coisa que eu nunca esperava. E fui empurrado para mexer na política, dois anos depois de ter sido campeão mundial [...] acabei ficando 16 anos como vereador. E fiquei três mandatos trabalhando como político. (A2).

Sou comentarista esportivo e continuo fazendo eventos e palestras. Eu dei aula de escolinha de futebol, depois saí pelo Brasil dando palestras, eventos. [...] trabalhei no Mineirão (estádio de futebol) como funcionário. Sempre gostei de estar envolvido no meio esportivo. (A4).

\section{Apoio para o término da carreira}

Quanto ao apoio para encerrar a carreira esportiva, cinco dos seis ex-atletas ressaltaram que a família foi a principal fonte. Apenas um dos entrevistados explicou que não teve nenhum tipo de suporte:

Foi a minha família que me deu o suporte. Minha esposa me acompanha em tudo, minha companheira [...]. A ajuda maior foi antes de parar de jogar futebol, fazendo com que eu me preparasse, me articulasse, montar academia. Minha família me ajudou muito, sou muito grato por isso. (A6).

Não, eu que corri atrás. Posso dizer que não tive apoio depois de parar de jogar, tive que correr atrás mesmo, corri muito atrás [...]. Quando você para de jogar, muitos não se preocupam se você precisa de algo. (A1).

Um dos ex-atletas ressaltou que um dos clubes no qual ele jogou forneceu suporte para a reinserção no mercado de trabalho.

Minha família me apoiou muito, tive o apoio dos clubes no final da minha carreira, tive oportunidade de trabalhar neles [...]. Alguns amigos, de um dos clubes que eu joguei, me deram muito apoio quando eu parei de jogar. Neste sentido não posso reclamar, os clubes sempre deixaram as portas abertas para mim. (A5).

\section{Discussão}

O objetivo do estudo foi analisar o término da carreira de ex-atletas de futebol que participaram de Copas do Mundo pela seleção brasileira entre 1966 e 1982. Em relação ao planejamento da carreira, os fatores que determinam o término da carreira influenciam na maneira como acontece a transição para o pós-carreira, podendo ser uma passagem sem grandes transtornos ou o início de uma crise existencial do atleta (TAYLOR; OGILVIE, 1994; KUETTEL; BOYLE; SCHMID, 2017).

Os ex-atletas da seleção brasileira que participaram do presente estudo não tiveram um planejamento estruturado para o término da carreira, nem tampouco pouco um acompanhamento profissional que os ajudasse nesse momento, ficando evidente a falta de apoio psicológico, social e financeiro. Fernández e Moreno (2012) encontraram resultados semelhantes em atletas de futebol espanhol: apenas um terço dos ex-atletas investigados no futebol espanhol planejaram o término de suas carreiras. Isto evidencia que independentemente das características culturais e sociais de um país, a falta de planejamento estruturado para o término da carreira esportiva é um problema mundial que afeta atletas profissionais de futebol (STAMBULOVA et al., 2009). 
Fica claro com esta amostragem de atletas da seleção brasileira que existe um paradoxo entre o pensamento e a ação durante o processo de transição da carreira esportiva. Os entrevistados reconheceram a importância do planejamento estruturado para o sucesso laboral após o término da carreira, porém eles não buscaram ajuda especializada para esse momento tão delicado de suas vidas. Entre os anos 60 e 80 do século passado eram reduzidos os programas e as entidades de assistência à carreira dos atletas. Uma das poucas entidades que existia nesse período era a Associação de Garantia do Atleta Profissional (AGAP). Porém, poucos atletas procuravam o auxilio dessa instituição. Além disso, os clubes não mantinham setores voltados para auxiliar os atletas a planejarem de forma estruturada o término da carreira. O esporte apresentava traços latentes de amadorismo e somente os atletas de destaque no futebol brasileiro tinham uma remuneração maior. No período investigado (entre 1966 e 1982), a grande maioria dos atletas que se destacavam no futebol brasileiro não se transferia precocemente para jogar em equipes do futebol internacional, principalmente na Europa (FERNANDES, 2009).

Fica evidente que os entrevistados enfrentaram dificuldades em conciliar a carreira esportiva e a formação escolar. Em um dado momento da carreira, esses atletas que obtiveram projeção e atuaram pela seleção brasileira priorizaram a carreira esportiva e os ganhos financeiros advindos da carreira profissional como atleta de futebol e deixaram em segundo plano a formação educacional. Também cabe ressaltar que o acesso ao ensino superior era restrito. Os indicadores educacionais da população brasileira entre 1966 e 1968 eram piores em relação aos dias atuais (BRASIL, 1972). No período investigado neste estudo, não era comum atletas do futebol brasileiro conseguirem conciliar a carreira esportiva e os estudos, principalmente no âmbito universitário. Um dos entrevistados afirmou que não gostava de estudar, mesmo tendo algumas oportunidades para concluir o ensino médio. Recentemente, resultados semelhantes foram verificados em ex-atletas profissionais do futebol brasileiro, já que eles também priorizaram a carreira esportiva em detrimento da formação educacional (COSTA et al., 2010), realçando o fato de que independentemente do período avaliado existem evidências que apontam para um processo de desinteresse na busca da formação educacional por parte dos atletas de futebol no Brasil. Na mesma linha de raciocínio, Carlin e Ruiz (2012) reforçam a importância dos programas de assistência à carreira esportiva ao redor do mundo para que atletas consigam planejar de forma adequada o término da carreira, demonstrando que este é um problema crônico enfrentado em vários países.

Grande parte dos atletas de futebol no Brasil, depois da aposentadoria nos gramados, apresenta dificuldades de reinserção profissional devido ao baixo nível educacional e de qualificação (COSTA et al., 2010). Um estudo com atletas brasileiros juniores de futebol também identificou esse problema (MARQUES; SAMULSKI, 2009). Isso nos leva a concluir que independentemente da época, do estágio na carreira e do status alcançado pelo atleta de futebol, no Brasil existe um problema sistêmico educacional e de qualificação profissional que afeta todo o processo de planejamento da carreira e, consequentemente, o seu término.

Evidências apontam que a dupla jornada, ou seja, conciliar a carreira esportiva com os estudos é um caminho viável para que atletas tenham menor dificuldade de readaptação após o término da carreira esportiva. Vilanova e Puig (2014) verificaram a trajetória de ex-atletas olímpicos e constataram que aqueles que faziam um grande esforço para continuar estudando durante a carreira tinham melhores chances no mercado de trabalho após o término da carreira, mostrando a relação existente entre a colocação no mercado e a qualificação profissional. O estudo de Zhang et al. (2013), com ex-atletas chineses de elite de diferentes esportes, revelou que a maior parte deles $(65 \%)$ procurou fazer um curso universitário para melhorar as chances de encontrar um bom emprego depois da aposentadoria.

As lesões foram citadas como as principais causas para o término da carreira esportiva dos ex-atletas entrevistados. Entre 1966 e 1982, a medicina, a fisiologia e a fisioterapia 
esportiva eram ciências incipientes e pouco presentes no contexto diário dos clubes. Existia um número reduzido de profissionais especializados em lesões no futebol. Este fator aumentava a taxa de abandono da carreira em função de um quadro grave de lesão. Evidências apontam que a frequência de ocorrência de lesões e a imprevisibilidade delas podem antecipar e acelerar o término da carreira esportiva e, consequentemente, o planejamento da transição entre a carreira como atleta e outra atividade na sociedade (CAPRARO; CAVALCANTI; de SOUZA, 2011; PARK; TOD; LAVALLEE, 2012). Durante a carreira esportiva dos entrevistados os métodos de preparação física eram pouco específicos. Tal situação também pode ter contribuído para o abandono precoce da carreira esportiva por parte dos entrevistados. O desgaste físico proveniente da prática de futebol profissional pode gerar lesões e um estado de dor crônica que ameaça, além de antecipar a aposentadoria, acompanhar o atleta ao longo da vida mesmo depois da aposentadoria (ARLIANI et al., 2014).

A idade avançada também foi outro fator apontado pelos ex-atletas que contribui para o término da carreira esportiva. Antigamente, os atletas de futebol encerravam a carreira por volta dos 30 anos de idade, ou seja, a longevidade era menor do que nos dias atuais. Os atletas eram submetidos a métodos de treinamento e de controle e monitoramento da carga menos avançados em comparação aos dias atuais. Tal contexto pode ter afetado a longevidade da carreira esportiva dos entrevistados. Agresta, Brandão e Barros Neto (2008) também identificaram um resultado semelhante ao constatar que a idade avançada influenciou decisivamente no término da carreira de ex-atletas profissionais do futebol brasileiro. De acordo com o estudo acima, a perda do condicionamento físico, a falta de motivação para treinar e competir, a rotina de jogos e os inúmeros anos de treinamento, associados ao avançar da idade, são fatores determinantes para o fim deste ciclo.

A saturação psicológica foi outro fator relatado pelos ex-atletas que influenciou o término da carreira. Naquela época, a saturação era advinda de longas viagens realizadas pelas equipes e também pela seleção brasileira. As excursões ao exterior e o período de preparação e concentração para as Copas do Mundo podiam durar meses. Também existia uma escassez de recursos de comunicação para os atletas fazerem contatos com seus familiares e amigos. Após vários anos de envolvimento com o esporte de alto rendimento, é comum atletas se sentirem saturados emocional, comportamental e cognitivamente (STAMBULOVA; WYLLEMAN, 2014). Nesse sentido, um estudo com 25 ex-atletas de futebol do Reino Unido mostrou que muitos desses indivíduos se sentiram aliviados por não precisar mais se submeter à cansativa rotina de jogos e treinamentos depois da aposentadoria (JONES; DENISON, 2016). A família e as obrigações oriundas da carreira esportiva são tipicamente razões para uma livre escolha de encerrar a carreira esportiva (STAMBULOVA; WYLLEMAN, 2014). Confrontando os resultados do presente estudo com os trabalhos supracitados, observa-se uma sinergia entre os argumentos apresentados pelos ex-atletas entrevistados e as evidências apontadas na literatura.

Os entrevistados tiveram outras ocupações laborais após o término da carreira. Eles, aproveitando-se do status de ex-atletas de seleção brasileira, trabalharam como comentaristas, cronistas esportivos ou empresários no ramo esportivo. Também cabe ressaltar que durante aquele período não existia a regulamentação profissional da Educação Física (CONFEF, 2018). Assim, os ex-atletas também tinham como mercado de trabalho as escolinhas de esportes, projetos sociais, equipes de categoria de base e profissional. Estudos apontam que o ambiente esportivo é o mais desejado e valorizado pelos ex-atletas para trabalhar, especialmente para aqueles que não conseguiram uma formação acadêmica (LOTYSZ; SHORT, 2004, VILANOVA; PUIG, 2014). Costa et al. (2010) afirmam que aproximadamente $60 \%$ dos ex-atletas brasileiros de futebol encontraram no meio esportivo uma forma de continuar trabalhando e garantir os dividendos para a sobrevivência. 
Apesar de servirem seleção brasileira e isto gerar uma ausência física dentro do âmbito familiar, os atletas avaliados relataram que a família (em especial esposa e filhos) foi a principal fonte de apoio para o término da carreira. Tal constatação também foi encontrada em outros estudos (COSTA et al., 2010; FERNÁNDEZ; MORENO, 2012), que registraram a família como um elemento crucial de suporte emocional e social na vida do ex-atleta.

A dificuldade de entrevistar, para fins científicos, ex-atletas que chegaram à seleção brasileira de futebol entre 1966 e 1982 foi o principal fator limitante do presente estudo. Muitos ex-atletas contatados não aceitaram participar da presente investigação em função de vários motivos, como não gostar de falar sobre a carreira e indisponibilidade de tempo para participar de um estudo científico. Outra limitação desta investigação refere-se ao fato de que os dados coletados foram exclusivamente baseados nos relatos retrospectivos dos ex-atletas. Não foram feitas confrontações de informações com terceiros ou com o material jornalístico da época, o que gera um resultado baseado unicamente na percepção subjetiva dos entrevistados.

Entretanto, cabe ressaltar que o presente estudo fornece uma importante contribuição de registro histórico e de avanço do estado da arte sobre a transição da carreira esportiva, já que foi pioneiro em analisar o término da carreira de ex-atletas de futebol que alcançaram o status de servir a seleção brasileira em Copas do Mundo.

\title{
Considerações finais
}

Conclui-se que os ex-atletas da seleção brasileira de futebol que participaram deste estudo não planejaram a carreira esportiva de forma estruturada e profissional, o que trouxe prejuízos para a readaptação da maior parte dos entrevistados a um novo contexto social. A formação educacional não era prioridade para os entrevistados durante a carreira esportiva. Os motivos que levaram ao término da carreira esportiva são multifatoriais e vão desde a saturação psicológica, lesões até idade avançada para os padrões da época. $\mathrm{Na}$ aposentadoria esportiva, os entrevistados se envolveram em outras atividades dentro e fora do ambiente esportivo. A família foi o principal fator de apoio para que enfrentassem os desafios inerentes a este novo estágio de vida.

\section{HOW HAS OCCURRED THE PROCESS OF FORMER FOOTBALL ATHLETE'S CAREER TERMINATION WHO PLAYED IN FOOTBALL WORLD CUPS FOR BRAZIL BETWEEN 1966 AND 1982?}

\begin{abstract}
This study aimed to analyze the end of the career of former soccer players who competed in World Cup for Brazil between 1966 and 1982. Semi-structured interviews were conducted with six former athletes. The interviews were analyzed by means of meaning-units. The content of the interview was organized into five categories. The results indicate that the former athletes did not have access to a professional structure to plan for after the end of their career. They failed to reconcile their sports career with their studies. The described reasons for the end of careers included psychological saturation, injuries, and old age. The interviewees had several post-career occupations, many of them related to the sports environment. Their families were the greatest source of support during the end of their careers. It is concluded that the causes of the retirement of the interviewees were multifactorial, and that the former athletes did not have a structured plan for after the end of their sports career
\end{abstract}

Keywords: Retirement. Athletes. Soccer. 


\title{
¿CÓMO HA OCURRIDO EL PROCESO DE EL TÉRMINO DE LA CARRERA DE- PORTIVA DE EX ATLETAS DE FÚTBOL QUE JUGARON COPAS DEL MUNDO POR EL EQUIPO DE BRASIL ENTRE 1966 Y 1982?
}

\begin{abstract}
Resumen
El propósito del estudio fue analizar el término de la carrera de ex atletas de fútbol que disputaron Copas del Mundo por Brasil entre 1966 y 1982. Se realizaron entrevistas semiestructuradas con seis ex atletas. Las entrevistas se analizaron por medio de miniunidades. El contenido de la entrevista se organizó en cinco categorías. Los resultados apuntan que los ex atletas no tuvieron acceso a una estructura profesional para planificar el término de la carrera. Ellos no consiguieron conciliar la carrera deportiva con los estudios. Los motivos mencionados para el término de la carrera fueron: la saturación psicológica, lesiones y edad avanzada. Los entrevistados tuvieron diversas ocupaciones en el periodo posterior a la carrera, muchas de ellas relacionadas con el medio deportivo. La familia fue la mayor fuente de apoyo durante el término de la carrera. Se concluye que las causas de la jubilación de los entrevistados fueron multifactoriales y que los ex atletas no tuvieron una planificación estructurada para el término de la carrera deportiva.
\end{abstract}

Palabras clave: Jubilación. Atletas. Fútbol.

\section{Referências}

ARLIANI, G. et al. Impact of sports on health of former professional soccer players in Brazil. Acta Ortopédica Brasileira, São Paulo, v. 22, n. 4, p. 188-190, jul. 2014. Disponível em: $<$ http://www.scielo.br/scielo.php?script=sci_arttext\&pid=S1413-78522014000400188>.

Acesso em: 13 fev. 2016.

AGRESTA, M. C.; BRANDÃO, M. R.; BARROS NETO, T. L. Causas e consequências físicas e emocionais do término de carreira esportiva. Revista Brasileira de Medicina e Esporte, São Paulo, v. 14, n. 6, p. 504-508, nov./dez. 2008. Disponível em: <http://www.scielo.br/pdf/rbme/v14n6/a06v14n6.pdf>. Acesso em: 10 fev. 2016.

BRASIL. Ministério da Educação e Cultura. Serviço de Estatística da Educação e Cultura, Estatística da Educação Nacional, 1960-71. Brasília, DF, 1972.

CAPRARO, A. M.; CAVALCANTI, E. A.; de SOUZA, D. L. "Cai o pano": uma análise do encerramento da carreira de Ronaldo "fenômeno" a partir de duas mídias digitais esportivas. Movimento, Porto Alegre, v. 17, n. 3, p. 175-192, jul/set de 2011. Disponível em: <http://www.seer.ufrgs.br/index.php/Movimento/article/view/21204/14378>. Acesso em: 10 fev. 2016.

CARLIN, M.; RUIZ, E. Transición de carrera deportiva a un nuevo contexto vital: perspectivas actuales. Cuadernos de Psicología del Deporte, Múrcia, v. 12, n. 1, p. 103-110, jun. 2012.

CONSELHO NACIONAL DE EDUCAÇÃO FÍSICA (CONFEF). Disponível em: <http:// http://www.confef.org.br/confef/legislacao/25>. Acesso em: 13 mar. 2018. 
COSTA, V. T.; FERREIRA, R. F.; PENNA, E. M.; COSTA, I. T.; SAMULSKI, D. Fases de transição da carreira esportiva: perspectiva de ex-atletas profissionais do futebol brasileiro. Conexões: Revista da Faculdade de Educação Física da UNICAMP, Campinas, v. 8, n. 3, p. 84-103, set./dez. 2010. Disponível em: http://periodicos.sbu.unicamp.br/ojs/index.php/conexoes/article/view/8637729>. Acesso em: 15 fev. 2016.

CÔTÉ, J.; ERICSSON, K; LAW, M. Tracing the development of athletes using retrospective interview methods: a proposed interview and validation procedure for reported information. Journal of Applied Sport Psychology, Abingdon, v. 17, n. 1, p. 1-19, mar. 2005.

CÔTÉ, J.; SALMELA, J.; BARIA, A. RUSSEL, S. Organizing and interpreting unstructured qualitative data. The Sport Psychologist, Champaign, v. 7, n. 2, p. 127-137, jun. 1993.

FERNANDES, E. B. Análise da participação dos clubes nacionais e internacionais na cessão de jogadores à Seleção Brasileira de Futebol nas Copas do Mundo de 1970 a 2006. Revista Brasileira de Futebol, Viçosa, v. 2, n. 2, p. 27-39, jul./dez. 2009. Disponível em: < http://www.seer.ufv.br/seer/rbf/index.php/RBFutebol/article/view/59/55>.

Acesso em: 25 fev. 2016.

FERNÁNDEZ, M. L.; MORENO, M. R. Recursos disponibles para la inserción sociolaboral tras la retirada deportiva de futebolistas. Revista de Psicología del Deporte, Palma, v. 21, n, 1, p. 189-194, jan. 2012.

HACKFORT, D.; EMRICH, E.; PAPATHANASSIOU. V. Nachsportliche Karriereverläufe. Eine Untersuchung $\mathrm{zu}$ berufsbezogenen Karrieren ehemaliger Spitzensportler. Schorndorf: Hofmann, 1997.

KUETTEL, A.; BOYLE, E.; SCHMID, J. Factors contributing to the quality of the transition out of elite sports in Swiss, Danish, and Polish athletes. Psychology of Sport and Exercise, Amesterdã, v. 29, p. 27-39, jan. 2017.

JONES, L.; DENISON, J. Challenge and relief: a foucauldian disciplinary analysis of retirement from professional association football in the United Kingdom. International Review for the Sociology of Sport, Thousand Oaks, v. 51, n. 1, p. 1-16, fev. 2016.

\section{LAZARUS, R.; FOLKMAN, S. Stress appraisal and coping. New York: Springer, 1984}

LOTYSZ, G.; SHORT, S. "What ever happened to...": the effects of career termination from the national football league. Athletic Insight, New York, v. 6, n. 3, p. 47-66, dec. 2004.

MARQUES, M.; SAMULSKI, D. Análise da carreira esportiva de jovens atletas de futebol na transição da fase amadora para a fase profissional: escolaridade, iniciação, contexto sóciofamiliar e planejamento da carreira. Revista Brasileira de Educação Física e Esporte, São Paulo, v. 23, n. 2, p. 103-119, jul./set. 2009. Disponível em: <http://www.revistas.usp.br/rbefe/article/view/16714>. Acesso em: 11 mar. 2016, 
PARK, S.; TOD, D.; LAVALLEE, D. Exploring the retirement from sport decision-making process based on the transtheoretical model. Psychology of Sport and Exercise, Philadelphia, v. 13, n. 4, p. 444-453, jul. 2012.

PATTON, M. Qualitative research \& evaluation methods: integrating theory and practice. 4 ed. Thousand Oaks: Sage, 2015.

SAMULSKI, D. et al. Análise das transições das carreiras esportivas de ex-atletas de alto nível. Motriz, Rio Claro, v. 15, n. 2, p. 310-317, abr./jun. 2009. Disponível em: <http://www.revistas.usp.br/rbefe/article/view/16714/18427>. Acesso em: 11 mar. 2016.

SILVA JÚNIOR, A. S.; SALAZAR; V. S.; FEITOSA, M. G. O clube dos 13 e o novo cenário do futebol brasileiro: uma análise a partir dos campeonatos baiano, goiano, paranaense e pernambucano. Revista Brasileira de Ciências do Esporte. Florianópolis, v. 36, n. 1, p. 103122, jan./mar. 2014. Disponível em: < http://www.scielo.br/pdf/rbce/v36n1/0101-3289-rbce36-01-00103.pdf>. Acesso em: 12 jan. 2016.

STAMBUlOVA, N.; AlFERMANN, D.; STATlER, T.; CÔTÉ, J. ISSP Position Stand: career development and transition of athletes. International Journal of Sports and Exercise Psychology, Abingdon, v. 7, n. 4, p. 395-412, set. 2009. Disponível em < http://www.issponline.org/documents/positionstand2010-1.pdf> Acesso em: 12 jan. 2016

STAMBULOVA, N.; WYLLEMAN, P. Athletes' career development and transitions. In: PAPAIOANNOU, A.; HACKFORT, D. (Ed.). Routledge companion to sport and exercise psychology: global perspectives and fundamental concepts. 1. ed. London: Routledge, 2014. p. 605-620.

TAYLOR, J.; OGILVIE, B. A conceptual model of adaptation to retirement among athletes. Journal of Applied Sport Psychology, Abingdon, v. 6, n. 1, p. 1-20, jan. 1994.

TESCH, R. Qualitative research: analysis types and software tools. New York: Falmer Press, 1990, p. 330.

VILANOVA, A.; PUIG, N. Personal strategies for managing a second career: the experiences of Spanish olympians. International Review for the Sociology of Sport, Thousand Oaks, v. 49, n. 3, p. 1-18, jun. 2014.

WYLLEMAN, P.; ROSIER, N.; De KNOP, P. Career transitions. In: SCHINKE, R.; MACGANNON, K.; SMITH, B. (Ed.). Routledge international handbook of sport psychology. 1. ed. London: Routledge, 2016. p. 111-118.

ZHANG, F.; ANDRADE, F.; QIU, J.; ZHU, W. Career transitions and social mobility among chinese elite athletes. Asian Journal of Exercise \& Sports Science, Urbana, v. 10, n. 2, p. 24-35, jul./dez. 2013. Disponível em <http://atheneforschung.unibw.de/doc/85354/85354.pdf> Acesso em: 12 jan. 2016.

Recebido em: 09/05/2017

Revisado em: 10/08/2017

Aprovado em: 11/08/2017 
Endereço para correspondência:

vtcosta@hotmail.com

Varley Teoldo da Costa

Universidade Federal de Minas

Av. Pres. Antônio Carlos, 6627

- Pampulha, Belo Horizonte - MG, 31270-901 